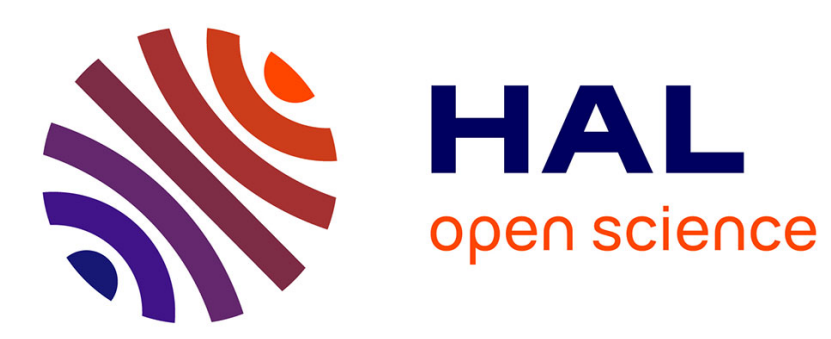

\title{
Effects of Tropical Climate on Mental Rotation: The Role of Imagery Ability
}

Nicolas Robin, Guillaume R. Coudevylle, Olivier Hue, Stéphane Sinnapah

\section{To cite this version:}

Nicolas Robin, Guillaume R. Coudevylle, Olivier Hue, Stéphane Sinnapah. Effects of Tropical Climate on Mental Rotation: The Role of Imagery Ability. American Journal of Psychology, 2017, 130 (4), 10.5406/amerjpsyc.130.4.0455 . hal-01633115

\section{HAL Id: hal-01633115 https://hal.science/hal-01633115}

Submitted on 11 Nov 2017

HAL is a multi-disciplinary open access archive for the deposit and dissemination of scientific research documents, whether they are published or not. The documents may come from teaching and research institutions in France or abroad, or from public or private research centers.
L'archive ouverte pluridisciplinaire HAL, est destinée au dépôt et à la diffusion de documents scientifiques de niveau recherche, publiés ou non, émanant des établissements d'enseignement et de recherche français ou étrangers, des laboratoires publics ou privés. 
Running head: MENTAL ROTATION, IMAGERY ABILITY AND TROPICAL CLIMATE

1

2

3

4

9

14
Effects of Tropical Climate on Mental Rotation: The Role of Imagery Ability

Nicolas Robin, Guillaume R. Coudevylle, Olivier Hue, and Stephane Sinnapah.

University of French West Indies, Department of Sport Sciences, Pointe-à-Pitre, France.

Correspondence concerning this article should be adressed to Nicolas Robin, Laboratoire

"Adaptation au Climat Tropical, Exercice \& Santé" (UPRES EA 3596), Campus Fouillole, BP 592, 97159, Pointe à Pitre Cedex, France.

Contact: robin.nicolas@hotmail.fr 
2 This study examined how a tropical climate (i.e., hot and wet climatic environment) could

3 affect mental rotation according to imagery ability. The participants performed two tests

4 sessions in quite hot temperature: Tropical Climate (TC) then in Air Conditioning (AC) in a

5 randomized order. During each session, the participants fulfilled the Movement Imagery

6 Questionnaire Revised version (MIQ-R) and the Vandenberg Mental Rotation Test (VMRT).

7 A first analysis including all the participants revealed that men had better VMRT scores than women in AC which confirm the gender effect generally observed. However, no statistical gender difference was observed in TC in which men deteriorated their performance. A second analysis including MIQ-R scores, as participant selection, evidenced a significant interaction between imagery ability and climate condition and revealed that poor imagers had worse VMRT scores in TC than in AC, whereas no significant difference was observed for good imagers. Moreover, MIQ-R scores were lower in TC than in AC for the visual and kinaesthetic imagery. More precisely, good imagers had significant lower visual imagery MIQ-R scores in TC than in AC and poor imagers tend to deteriorate their kinaesthetic imagery MIQ-R scores in TC. The results of this study are consistent with the idea that TC can negatively affect mental rotation, motor imagery and imagery ability and the influence of TC on them is discussed. Further research is needed to investigate the hygrometry effects on imagery.

Keywords: mental rotation, imagery ability, tropical environment, gender 
Effects of Tropical Climate on Mental Rotation: The Role of Imagery Ability Since the early days of imagery research, many authors have been interested in imagery ability. One reason for the interest may be that virtually everyone seems to have the ability to generate and use images, but not to the same degree (Goss, Hall, Buckolz, \& Fishburne, 1986). Different methods were used to evaluate the ability to generate image. Shepard and Metzler (1971) first used the term of Mental Rotation (MR). This is the ability to make the mental image of a given $2 \mathrm{D}$ or $3 \mathrm{D}$ object turn in space. M R allows subjects to compare the structure of two objects in considerable detail without completely understanding the structure of either one (Just \& Carpenter, 1985). According to Logie, Pernet, Buonocore, and Della Sala (2011), healthy adults might use mental imagery to perform mental rotation, but other might use a propositional strategy. Just and Carpenter (1985) added that it is possible to perform MR task by using orientation-free descriptions with no spatial manipulation. However, Hegarthy \& Waller (2004) argued that in MR tests the majority of participants reports imagining the rotations of the objects, and not themselves, and Wexler, Kosslyn and Berthoz (1998) added that the most common strategy to accomplish these tasks is rotation.

There is accumulated evidence of some gender differences in adult MR ability with men generally outperforming women (e.g., Hoyek et al., 2009; Ozel, Molinaro, \& Larue, 2001; Vandenberg \& Kuse, 1978). Gender cognitive difference like that observed in MR are also reported in other studies (Gaoua, 2010; Gur et al., 1999; Hancock \& Vasmatzidis, 2003; Koslow, 2004) but two of them catch our attention. In the first one, Wyon, Anderson and Lundqvist (1972) reported that females could better withstand the negative effects of heat stress than males. In the second one, Lan, Lian, Liu \& Liu (2008) found that males prefer cooler room temperature than females who furthermore are less sensitive to hygrometry. We are particularly interested in these results because the gender effect in MR was observed in 
1 neutral climate. Given that male and female reported differences in temperature and

2 hygrometry acceptance, we may postulate that tropical climate (i.e., hot and wet climatic environment) could alter the gender effect observed in neutral condition. Our primary aim was to replicate the gender effect in Air Conditioning (AC), a condition similar to neutral climate used in most of MR studies. We also examined if the gender effect was replicated in Tropical Climate (TC). The influence of this hot environment on MR ability will be more precisely developed in the following paragraph. We predicted that the females, although they have fewer MR performances than males as in AC, would be less affected by a hot and humid environment than males.

Kosonen and Tan (2004) suggested that thermal environment (including heat and hygrometry) is one of the most important indoor environmental factor that affect human mental performance as work productivity. According to many authors, heat stress is associated with decreased performance across multiple tasks (Berg et al., 2015; Gaoua, 2010; understood, modeled and documented (Hancock \& Vasmatzidis, 2003). In contrast, despite a growing body of experimental studies in this area, the effects of heat stress on human cognitive abilities are less well understood. Ramsey and Kwon (1992) confirmed that simple mental tasks show little, if any, decrement in the heat. They added that, more difficult tasks (perceptual motor tasks) show the onset of decrements the range between $30-33^{\circ} \mathrm{C}$, regardless of the duration of exposure. Qian and collaborators (2015) proposed that heat stress has a 21 potential fatigue-enhancing effect when individual is performing highly cognition-demanding 22 attention task. Moreover, Gaoua (2010) found that there was an impairment in working memory and suggested that exposure to a hot environment is a competing variable to the cognitive processes. According to Tomasino and Gremese (2016), MR is a complex cognitive task that imply working memory and requires cognitive manipulation, comparison and spatial 
1 transformation of the imagined object (Guillot, Champely, Batier, Thiriet \& Collet, 2007,

2 Wexler et al., 1998). We could therefore hypothesize that heat stress, which is well known to

3 negatively influence performance in complex tasks, would also influence MR ability. MR is

4 known to enhance motor performance (Hoyeck, Collet, Fargier, \& Guillot, 2012), spatial

5 route learning (Moffat, Hampson, \& Hatzipantelis, 1998), math achievement (Voyer, 1996) or

6 learning improvement (Hoyeck et al., 2009), that's why a better understanding and use of MR

7 would benefits numerous students, athletes and people living in TC. The second aim was to

8 evaluate whether tropical climate influences MR ability. We predicted that the performance of

9 the participants would be affected by the deleterious effect of a hot and wet climatic

10 environment.

According to Kosslyn, Thompson, Wraga and Alpert (2001), MR and Motor Imagery

12 (MI) activate similar (i.e., primary motor cortex area 4 ) and specific neural structures (for a review see Tomasino, \& Gremese, 2016) but are two complementary process (Hoyeck, Collet, \& Guillot, 2010, Sirigu, \& Duhamel, 2001). Wohlschlager and Wohlschlager (1998) provide a substantial direct link between motor process and mental image transformation. Moreover, Wexler et al. (1998) showed a specific detailed interaction between motor rotation of action and visual mental image using a dual-task paradigm in which subjects performed the CooperShepard mental rotation task while executing an unseen motor rotation. As suggested by Hoyeck et al. (2010), it could be considered that for a wide variety of sports and particularly in those using rotation (i.e., dance, judo or gymnastics), MR abilities are needed (Habacha, Molinaro, \& Dosseville, 2014), as it is also the case for MI (Schack, Essig, Frank, \& Koester, 2014). Finally, Sirigu and Duhamel (2001) concluded that MI contributes to MR in normal subjects.

According to Williams et al. (2012), MI is the mental representation or cognitive rehearsal of a motor act or movement in the absence of any overt motor output. It can 
1 facilitate learning, improve performance, increase muscle strength and also modify cognition

2 as regulation of arousal and anxiety (Cumming \& Williams, 2012; Guillot, Tolleron, \& Collet,

3 2010). It is now well established that the effectiveness of MI as a performance enhancing

4 strategy depends upon one's capacity to generate mental images of specific movements

5 (Seiler, Monsma, \& Newman-Norlund, 2015). According to the psychology literature, visual

6 (i.e., what an individual sees) and kinaesthetic (i.e., feeling or polysensory experience of the

7 body while performing a movement) are the two most common sensory modes of generating

8 images. A comprehensive yet inexpensive method of screening participants visual and

9 kinaesthetic imagery abilities is the use of self-report questionnaires (Goss et al., 1986; Hall,

10 Bernoties, \& Schmidt, 1995). According to Williams et al. (2012), one of the most popular

11 and commonly used questionnaires is the revised version of the Movement Imagery

12 Questionnaire (MIQ-R; Hall \& Martin, 1997). The MIQ-R is a briefer version of its

13 predecessor, the Movement Imagery Questionnaire (MIQ; Hall \& Pongrac, 1983). It assesses

14 the ability to mentally see and feel simple movements. In the Goss et al. (1986) study, of the

15219 subjects completing the MIQ, 22 fell into good imagery group and 19 fell into the poor

16 imagery group. It has been shown that individuals with higher levels of imagery ability "good

17 imagers" experience greater benefits from imagery compared with their lower level

18 counterparts "poor imagers" (Hall, Bernoties, \& Scmidt, 1995; Hall, Buckolz, \& Fishburne,

19 1989; Robin et al., 2007; Toussaint, Robin, \& Blandin, 2010). Authors concluded that a good

20 imagery ability allowed better and faster acquisition, learning and memory encoding than

21 poor imagery ability. The good versus poor imagers difference was confirmed using different

22 techniques as the measure of autonomic nervous response (Guillot, Collet, \& Dittmar, 2005)

23 or brain activity with functional magnetic resonance imaging (Guillot et al., 2008).

24 Consequently, based on Robin et al. (2007), we hypothesize that good imagers would have

25 better performance of a given task than poor imagers who have difficulties to build vivid 
1 mental images. Moreover, Guillot, and collaborators (2005) using a task of service return in

2 table tennis, investigated the effectiveness of motor imagery when performed in a context

3 close to actual practice situations rather than in a neutral environment. They showed that some

4 environmental conditions (i.e., tactile, kinaesthetic and auditory information's), helped

5 athletes to visualize and feel sensations elicited by actual practice. Specific environmental

6 conditions, can therefore have a beneficial effect on MI making coherent the hypothesis that

7 other conditions as TC which is characterized by a hot and wet climatic environment, could

8 degrade them in contrast. To date, the effect of TC on mental imagery, to our knowledge,

9 remains unstudied. As, the MIQ-R lacks of rotation movement, the use of the MR, together,

10 should be useful to permits a better evaluation of imagery process.

11 Results of MR studies have been inconsistent in showing a relationship between

12 variations in imagery ability and task performance (Richardson, 1980). For example, Logie et

13 al. (2011) observed that high and low imagers differed in error and in brain activation patterns

14 whereas Habacha and collaborators (2014) revealed no significant difference. Thus, the third

15 aim of the present paper was to evaluate whether the tropical climate influences MR upon

16 participants' imagery ability. We predicted that the mental rotation performance of good

17 imagers would be less affected by the deleterious effect of a hot and wet climatic environment 18 than that of poor imagers.

\section{Methodology}

\section{Participants}

One hundred and thirteen participants self declared right-handed gave their informed consent to participate in the study (62 females, 51 males; $M_{\text {age }}=22.87$ years, age range: 19 26 years). All were Guadeloupian students in the University of Antilles (in the French West Indies) living in the tropical environment throughout the year and were recruited by course credit. As many factors can influence mental performance, before each session, participants 
1 completed a control self-report questionnaire evaluating their sports activity (nature and

2 intensity, competitive level, consumption of medicine, drug, alcoholic and non-alcoholic

3 drinks in the $24 \mathrm{~h}$ preceding each experimental trial). Participants had recreational or club

4 sport level and none of the them revealed having a very high sport practice intensity or to be

5 thirsty before the sessions. Two participants were tested, but were excluded because they

6 reported the use of alcoholic drinks and medicine. The participants completed all the sessions,

7 but for the second statistical analyses including imagery ability, only 44 participants (25

8 females and 19 males) were selected $\left(M_{\text {age }}=21.75\right.$ years, $S D=1.42$ years $)$ with regard to

9 their MIQ-R scores: Bad imagers (13 females, 10 males; $\mathrm{n}=23$; scores < 18) and good

10 imagers (12 females, 9 males; $\mathrm{n}=21$; scores $>36$ ) groups (see Goss et al., 1986, for similar

11 participant selection).

12 Measures, Material and Task

Temperature. Tropical climate is characterized by consistently high monthly

temperatures, often exceeding $18^{\circ} \mathrm{C}$ throughout the year, and rainfall that exceeds

evapotranspiration for at least 270 days per year (Salati, Lovejoy, \& Vose, 1983). According

to the annual climatic bulletin (2015), these values varied across the day. For example,

between 10:00 am and 04:00 pm, indoor mean temperature can frequently reach $31 \pm 2{ }^{\circ} \mathrm{C}$

(hygrometry $=80 \% \pm 10 \% \mathrm{rH}$ ) but in air conditioning rooms the mean temperature generally

measured is $24 \pm 1^{\circ} \mathrm{C}$ (hygrometry $=45 \% \pm 5 \% \mathrm{rH}$ ). The present experiment was conducted

on a rectangular room $(5 \times 7$ meters $)$ where we can close the windows in order to elevate

temperature or use air conditioning to refresh temperature. Sessions were realized in an air

conditioning $(\mathrm{AC})$ condition $\left(\right.$ mean temperature $=24.06^{\circ} \mathrm{C}, S D=0.73$; and hygrometry $=46.5$

$\% \mathrm{rH}, S D=3.9)$ or tropical climate $(\mathrm{TC})$ condition (mean temperature $=31.04^{\circ} \mathrm{C}, S D=0.31$; and hygrometry $=71.2 \% \mathrm{rH}, S D=8.2$ ). Temperature and hygrometry were recorded with a 
$1 \mathrm{rH}$ beyond; temperature precision $\left.\pm 0.1^{\circ} \mathrm{C}\right)$.

Imagery. During each experimental session, all the participants completed the Movement Imagery Questionnaire-Revised (MIQ-R) (Hall \& Martin, 1997). The MIQ-R is a questionnaire assessing movement imagery ability for basic movements. The construct validity (factorial structure and internal consistency) and the test-retest reliability of the available French version were duly validated (Lorant \& Nicolas, 2004). It consists in a total of 16 items and two scales (i.e., the visual imagery scale and the kinaesthetic imagery scale). It contains seven items pertaining to visual imagery and seven items pertaining to kinaesthetic imagery. The actions to be performed, which are similar in the two scales, involve the upper limb, the lower limb, the whole body and actions in daily life. At the outset and for each item, the examiner reads to the participants a description of the movement to be carried out. Then, the participants are asked to actually perform the movement and then to either visually or kinaesthetically imagine it. Following this step, they are asked to rate how difficult/easy it was to imagine on two 7-point Likert-type scales $(1=$ very hard to see/feel and $7=$ very easy to seelfeel). Then, the items for each subscale are averaged, a higher score representing a greater ease of imaging.

Mental rotation test. During this experiment, we used the Vandenberg Mental Rotation Test (VMRT), elaborated by Vandenberg and Kuse (1978) from the original figures of Shepard and Metzler (1971). This test was translated in 1990 and standardized on a French population of high-school students by Albaret and Aubert (1996). This is a paper-and-pencil test of spatial visualization constructed from the figures used in the chronometric study of Shepard and Metzler (1971). The VMRT contains 20 items in five sets of four items. It consists of one reference figure on the left and four target figures on the right. The participants have to mentally rotate the target figures in space to find the two correct items that match the reference. 2 points are attributed for every line containing two correct choices 
1 and a scoring method discouraging guessing was used, credit being given for an item only if

2 both correct test figures were properly identified (see Albaret \& Aubert, 1996, for similar

3 procedure). The scores for each individual ranged from 0 to 40 . The test was to be completed

4 within a 6-minute period.

\section{Procedure}

The present experiment was conducted during a regularly scheduled class. All participants performed the procedure with a two-week interval between sessions, one in AC and one in TC. These conditions were presented in a randomized order. During each session, the participants completed the control questionnaire, the MIQ-R and the VMRT.

\section{Data Analysis}

For each participant, scores at the MIQ-R, and VMRT were measured. The dependent variables were submitted to ANOVAs (with repeated measures on the second factor) using the gender (female and male) as between-participants factor and the temperature condition (TC and $\mathrm{AC}$ ) as a within-participants factor and to ANOVAs (with repeated measures on the second factor) using the imagery ability (good and poor imagers) and gender (female and male) as between-participants factor and the temperature conditions (TC and AC) as a withinparticipants factor in a second time. Moreover, order effect was tested for all the groups. All significant main effects and interactions were broken down using the Newman-Keuls technique. We verified that all variables were normally distributed using KolmogorovSmirnoff test. Alpha was set at .05 for all analyses and effect sizes ( $\eta 2)$ were indicated.

\section{Results}

\section{Analyses on Mental Rotation}

ANOVA revealed a significant main effect of gender, $F(1,111)=9.79, \eta 2=0.08$, but did not reveal any significant main temperature condition, $F(1,111)=0.930, \eta 2=0.008$. 
2 interaction, $F(1,111)=6.80, \eta 2=0.06$. Post-hoc Newman-Keuls test revealed that men in

3 AC had better VMRT scores than men in TC and women in the two temperature conditions

4 whereas women VMRT scores in TC were not significantly different than those of women in $5 \quad$ AC and men in TC, (Figure 1).

6
Figure 1 near here

\section{Analyses on Mental Rotation after Imagery Ability Selection}

ANOVA did not reveal any significant main effect of imagery ability, $F(1,40)=$ 0.013, $\eta 2=0.00$, temperature condition, $F(1,40)=0.68, \eta 2=0.01$ or interactions between imagery ability and gender, $F(1,40)=0.001, \eta 2=0.00$, temperature condition and gender, $F(1,40)=0.74, \eta 2=0.01$ and temperature condition and imagery ability and gender, $F(1,40)$ $=0.63, \eta 2=0.01$.

However, the ANOVA revealed a significant imagery ability $\mathrm{x}$ temperature condition interaction, $F(1,40)=9.17, \eta 2=0.19$. Post-hoc Newman-Keuls test revealed that poor imagers had worse VMRT scores in TC than in AC, whereas there was no significant difference for good imagers (Figure 2).

ANOVA did not reveal any significant main effect of gender, $F(1,40)=2.54, \eta 2=0.05$, the mean men VMRT score was $13.98(S D=6.59)$, whereas the mean women VMRT score was $11.06(S D=5.96)$.

Figure 2 near here 
ANOVA revealed a significant main effect of visual imagery ability, $F(1,40)=99.9, \eta 2$

(Figure 3). ANOVA did not reveal any significant main effect of gender, $F(1,40)=2.06$, $\eta 2$

$4=0.04$, or interactions between imagery ability and gender, $F(1,40)=0.00, \eta 2=0.00$, $1)$.

temperature condition and imagery ability, $F(1,40)=0.08, \eta 2=0.00$, temperature condition and gender, $F(1,40)=1.83, \eta 2=0.04$ and temperature condition and imagery ability and gender, $F(1,40)=0.18, \eta 2=0.00$.

\section{Moreover, planned comparisons revealed that good imagers have worse visual imagery} MIQ-R scores in TC than in AC, $F(1,40)=5.08, \eta 2=0.12$. The mean visual imagery MIQ-R scores was 1.4 points inferior in TC than in AC, although there was no significant difference between conditions for poor imagers, $F(1,40)=2.83, p=.09, \eta 2=0.06$ (Figure 4 and Table

\section{Analyses on Kinaesthetic Imagery}

The ANOVA revealed a significant main effect of kinaesthetic imagery ability, $F(1,40)=$ 337.6, $\eta 2=0.97$ and temperature condition, $F(1,40)=5.48, \eta 2=0.12$ (Newman-Keuls, $p<$

$.05)$ (Figure 5). However, ANOVA did not reveal any significant main effect of gender, $F(1$, $40)=0.26, \eta 2=0.00$, or interactions between imagery ability and gender, $F(1,40)=0.52, \eta 2$ $=0.00$, temperature condition and imagery ability, $F(1,40)=0.16, \eta 2=0.00$ temperature condition and gender, $F(1,40)=0.07, \eta 2=0.00$ or temperature condition and imagery ability and gender, $F(1,40)=0.59, \eta 2=0.01$.

Moreover, planned comparisons revealed that poor imagers tend to have worse kinaesthetic imagery MIQ-R scores in TC than in AC, $F(1,40)=3.52, p=.067, \eta 2=0.08$ 
1 (the mean kinaesthetic imagery difference was 1.7 points see table 2 ), whereas there was no

2 significant difference between conditions for good imagers (Figure 6).

3

Figures 5, 6 and Table 2 near here

\section{Order Effect}

For all the groups, no order effect was observed between temperature condition $(p>.05)$.

\section{Discussion}

The primary aim of this study was to examine the effects of temperature condition and gender on MR ability. Many studies have shown evidence that males and females differ in their imagery generating capabilities (Ozel et al., 2001; Richardson, 1995; Hoyeck et al., 2009). The results of the current study, in AC condition, replicate the previously reported finding that men exhibit better spatial abilities than women. Two main factors might contribute to explain these gender differences: The "psychosocial" variety (stereotype threat, sex-role identification, experience and socialization) and the "biological" variety (e.g., sexual hormones) (Titze, Jansen, \& Heil, 2010). For example, Gur and collaborators (1999) observed that the percentage of gray matter is higher in females, while the percentage of white matter, and cerebrospinal fluid is augmented in males during imagery. According to this viewpoint, differences in cortical activation patterns and most especially hemispheric lateralization of brain activity were consistently reported (Seurinck, Vingerhoets, de Lange, \& Achten, 2004). An absence of gender difference in VMRT scores was observed in TC. However, the fact that men deteriorated their performance between $\mathrm{AC}$ and $\mathrm{TC}$ whereas women performance was not statistically different between these two conditions seems important to be considered and could be explained in various ways. Firstly, as hypothesized, we can presume that females can better withstand the negative effects of heat stress than males as 
1 argued by Wyon et al. (1979) and Lan et al. (2008). Moreover, the latter authors observed that

2 females are less sensitive to hygrometry than males. As referred to by Habacha et al. (2014),

3 we may envisage that the women used a different strategy than the men: As a matter of fact,

4 the men's use of holistic strategy may have been facilitated by life experience and

5 construction games (Alexander \& Evardone, 2008). Moreover a right hemisphere dominance

6 was observed in men while performing MR (for a review see Vogel, Bowers, \& Vogel, 2003),

7 whereas no difference was noted in women (while performing the same test) what seems to

8 suggest the use of a different strategy. We may consider that the women's strategy, though

9 less effective than that of the men, must have been less affected by TC. We can therefore

envisage that one or many of these possibilities might explain why women VMRT

11 performance was slightly affected by TC. On the contrary, males are more sensitive to heat

12 and prefer cool environment as suggested by Karjalainen (2011). Therefore, as proposed by

13 Lan et al. (2011), the negative effects of elevated temperature in TC, causing thermal

14 discomfort, have probably negatively influenced the performance in MR for males. Indeed,

15 the authors observed that when subjects felt warm, they assessed the air quality (heat and

16 hygrometry) to be worse, expressed more negative mood, and were less willing to exert effort.

17 Secondly, as suggested in the previous paragraph, hygrometry can influence mental

18 performance. Hygrometry is a variable that has drawn little attention in the heat stress

literature. Pepler (1958), one of the rare exceptions, tested tracking performance under high

$(80 \% \mathrm{rH})$ and low $(20 \% \mathrm{rH})$ conditions, each realized at four different temperatures $(22,26$,

2129 and $34^{\circ} \mathrm{C}$ ). The author identified a significant performance decline between $22^{\circ} \mathrm{C}$ and $26^{\circ} \mathrm{C}$

22 for the $80 \% \mathrm{rH}$ environment, and for the $20 \% \mathrm{rH}$ environment a significant decrement was

23 obtained between the highest temperatures of 26 and $29^{\circ} \mathrm{C}$. In the current study, the choice of

24 temperature in $\mathrm{AC}$ (mean temperature $=24.06^{\circ} \mathrm{C}$ ) and $\mathrm{TC}$ (mean temperature $=31.04^{\circ} \mathrm{C}$ ) was

25 made to come closest to local conditions in classroom of the University of Antilles. Because 
1 of the gap between between TC $71.2 \% \mathrm{rH}$ and $\mathrm{AC} 46.5 \% \mathrm{rH}$ (due to Air Conditioning

2 system), hygrometry may have influenced participants' cognitive performance, particularly

3 men. Indeed, Vasmatzidis, Schlegel, and Hancock (2002) found that, at $34^{\circ} \mathrm{C}$ (but not at

$\left.428^{\circ} \mathrm{C}\right)$, the high level of hygrometry $(70 \% \mathrm{rH})$ was more detrimental to time-sharing

5 performance than the lower level of $30 \% \mathrm{rH}$. A gender-based additional research is needed to

6 investigate the hygrometry effects on MR. For example, realizing the VMRT at $31^{\circ} \mathrm{C}$ and a

7 low level $(30 \% \mathrm{rH})$ should permit to dissociate the influence of heat and hygrometry on 8 gender.

Thirdly, we may envisage that the high performance participants variability $($ men $=$ 7.41, and women $=7.34 \mathrm{SD}$ ), in TC, did not allow to highlight a gender VMRT scores

11 difference. Gender effect could have been significant with more participants.

The second aim of the current study was to evaluate whether the tropical climate influences MR ability. This study was realized in TC partially characterized by hot environment. It is difficult to conclude whether heat exposure does (Cian et al., 2000; Ernwein \& Keller, 1998; Hocking, Silberstein, Lau, Stough, \& Roberts, 2001) or does not (Amos, Hansen, Lau, \& Michalski, 2000) have an adverse effect upon cognitive function and under what specific environmental conditions these alterations appear (Gaoua, 2011). It is generally shown that simple tasks such as reaction time are less vulnerable to heat stress than more complex tasks such as vigilance, tracking and multiple tasks performed together (Hancock \& Vasmatzidis, 2003). Tomasino et Gremese (2016) proposed that MR is a

21 complex cognitive task. Therefore, as hypothesized, heat stress would negatively influence 22 VMRT performance. The results obtained in this study, showing a significant decreased of performance for men in TC (in comparison to AC), partially confirm our hypothesis. This result indicates that TC can negatively influence MR. As previously suggested, the thermal discomfort caused by hot temperature and high hygrometry have probably negatively 
1 influenced the performance in MR in males. In fact, it is impossible to definitely assert

2 whether heat stress or hygrometry or both factors negatively influence MR performance. A

3 study in a climate chamber would permit to dissociate the influence of these two factors on

4 MR. Moreover, Hancock and Vastmatzidis (2003) argued that attention is a factor that must

5 be considered. Indeed, as the level of environmental stress increases (by increasing

6 temperature and hygrometry for example), attentional resources are progressively drained.

7 The fact that men deteriorated their VMRT performance in TC, in comparison to AC, should

8 be explained by the fact that TC imposes to them a supplementary constraint in term of

9 cognitive resources. The measure of attention besides MR and a comparison of the results

10 obtained in TC and AC, could permit to answer this question. Finally, Paivio (1985) proposed

11 that mental practice besides inducing cognitive processes that supplement those induced by

12 physical practice have a motivational role. It is therefore possible that thermal stress in TC

13 induces a central fatigue that negatively influences the men motivation in MR and MI as

14 suggested by Qian and collaborators (2015).

However, the absence of significant main effect of temperature condition (AC versus TC) on VMRT scores lead us to also wonder on task difficulty. MR task usually generates an

17 robust set of behavioral findings, with the time taken to respond to each stimulus pair increasing with the angle of rotation between them (Debarnot, Piolino, Baron, \& Guillot, 2013). We may envisage that lager angle rotations are most susceptible to be influenced by TC than smaller ones. However, the task used in our study did not investigate the angles of

21 rotation what can possibly mask the influence of TC. It is also possible that the VMRT was

22 not a rather complex task, like the mental transformation task evoked by Hancock and 23 Vasmatzidis (2003) which is less vulnerable to heat stress than more complex tasks. Indeed, 24 in Tomasino and Gremese (2016) study, the term of MR encompassed a large variety of tasks 25 using objects, body parts or combination of the two, for whom different factors can influence 
1 mental rotation operations. For example, the activation in the brain can be modulated by the

2 type of stimulus in MR task. Neuropsychological studies observed that different operations may be recruited in MR depending on whether the stimulus type is a two or three-dimensional object or a body part (Kosslyn, Di Girolamo, Thompson, \& Alpert, 1998). We may envisage that the specific operations used to resolve the VMRT was moderately influenced by TC and it is possible that another MR test using other strategies and more complex operations should be more affected by this environment. Further research are needed in order to investigate whether TC differentially influence several MR tests using different type of stimulus and strategy.

The third aim of the current study was to evaluate whether tropical climate influences VMRT scores upon participants imagery ability. Our results are consistent with those of Habacha et al. (2014) who observed that high and low imagers performed equally well on this test and those of Logie and collaborators (2011) who observed similar mean response times for high and low imagers in a mental rotation task. However, the latest authors reported that low imagers exhibit less accuracy for large angle rotations of images than for small angle rotations. In contrast with the task used by Logie et al. (2011), the VMRT used in our study did not investigate the angles of rotation but the accuracy of the answers. These authors concluded that poor imagers probably used a different strategy to solve the task than good imagers and that their strategy was prone to error. In their study, participants were permitted as much time as they needed to complete each trial. Thus, they had time to use their own strategies to solve the task. In contrast, the participants in our experiment were given only 6 min to complete the VMRT (as recommended by Albaret \& Aubert, 1996). As Habacha and collaborators (2014), which used the same time constraint, we may envisage that participants were under time pressure, which has the potential to affect scores on mental rotation tasks (Voyer, 1997). Consequently, as suggested by Habacha et al. (2014), it is likely that in the 
1 VMRT, most of the participants used similar strategies, specifically the one recommended by

2 the experimenter (i.e., "try to rotate one object until it is aligned with the other"). A

3 questionnaire assessing the different MR strategies used in the VMRT would have allowed to 4 answer the question.

The significant interaction observed, in this study, between imagery ability and

6 climate condition revealing that poor imagers had worse VMRT scores in TC than in AC

7 reinforces the fact that it is necessary to take climate condition into account when measuring imagery ability which is particularly affected by environmental conditions. Indeed MIQ-R scores were worse in TC than in AC for the visual and kinaesthetic imagery. As suggested by Guillot et al. (2005) it seems important to consider the environment in which mental imagery

11 is realized. Moreover, Logie et al. (2011) revealed that poor and good imagers activate networks differently in mental rotation. These results are consistent with Guillot et al. (2008) who observed the activation of common cerebral structures, but more diffuse neural networks on poor imagers, as well during the real execution so as during the motor imagery. Such findings reinforced the hypothesis that it is important to measure individual imagery ability differences. Previous studies have shown that this factor influences the ease with which simple movements patterns can be learned (Goss et al., 1986), and improves the impact of motor imagery upon the accuracy of complex motor tasks (Isaac, 1992). In a tennis task, Robin et al. (2007) showed that good imagers had better performance than poor imagers after a motor imagery learning process. Poor imagers can benefit from an imagery practice but they might need more trials to become as effective as good imagers (Goss et al., 1986). Moreover they have to previously develop a sensory-specific representation of actions to successfully employ MI as suggested by Toussaint et al. (2010). 
1 therefore important to take the temperature condition in which imagery ability questionnaires

2 are realized into account. Indeed, good imagers had significant lower visual imagery MIQ-R

3 scores in TC than in AC. Moreover, although being weak, we observed a decrease of MIQ-R

4 visual imagery performance in TC in comparison to AC in poor imagers (see Table 1). These

5 results could be explained by the Maximal Adaptability Model (Hancock \& Warm, 1989),

6 which assumes that heat exerts its detrimental effects on performance by competing for and

7 eventually draining attentional resources. Moreover, the fact that TC tend to deteriorate the

8 poor imagers kinaesthetic imagery MIQ-R scores, whereas the performance of good imagers

9 was less affected (see Table 2) could be explained by the fact that not only does TC makes it

10 more difficult for poor imagers to generate vivid and accurate kinaesthetic images of action

11 but it also imposes on them further constraint in term of cognitive resources. For example, in

12 a recent study, Chase, Karwowski, Benedict, Quesade, and Irwin-Chase (2003) reported poor

13 task performance at $35^{\circ} \mathrm{C}$ due to the inability of the participants to successfully allocate

14 attention to the tasks of the study. According to Hocking and collaborators (2001) the

15 performance in the cognitive tasks would deteriorate when the total resources are insufficient

16 for both the task and the thermal stress. We may suppose that this was the case when poor

17 imagers had to realize kinaesthetic imagery in TC. The fact that good imagers kinaesthetic

18 imagery was less affected by TC could be explained by the fact that the addition of the

19 resource needed for mental imagery plus the resources assigned for thermal stress do not

20 overtake the total resources of Global Workspace. Further research is needed to test the

21 influence of $\mathrm{TC}$ on attentional process.

22 Finally, the gender differences, in VMRT scores, with men outperforming women

23 were not observed when participants were selected on the basis of their MIQ-R scores. Logie

24 et al. (2011) examined the difference between good and poor imagers in a mental rotation task

25 and no gender effect according to imagery ability was reported. Many authors (Lorant \& 
1 Nicolas, 2004; Monsma, Short, Hall, Gregg, \& Sullivan, 2009; Williams et al., 2012) have

2 already demonstrated that there does not exist a significant difference between men and women as regards motor imagery ability and this finding was corroborated in our sample.

One limit of this study could be the relatively small number of participants selected on the basis of their MIQ-R scores (i.e., 40). However most of studies using the MIQ or MIQ-R, used the same strict selection criteria (Goss et al., 1986; Robin et al., 2007; Toussaint et al., 2010). For example, in Goss et al. (1986) study only 22 participants were selected as good imagers and 19 as poor imagers, all other participants being in intermediate category. VMRT, that are two pencil-paper test, was done because they can be realized everywhere, and can be beneficial in the field of sport and education. Moreover, they are the two most commonly used and validated in French tests, which is not the case of all the "English" tests that are not available in French validated version. For example, the use of the VMRT was reported in numerous studies (Debarnot et al., 2013; Habacha et al., 2011; Hoyeck et al., 2012). However, according to Logie et al. (2011), in MR task, participants might use mental imagery to perform mental rotation, and others might use a propositional strategy for the same task. Indeed, both strategies are available. The existence of multiple strategies may explain why it was difficult to convincingly demonstrate the discriminant validity of the visualization and spatial orientation factors (Just \& Carpenter, 1985). Contrary to Habacha et al. (2014) who suggested that participants had similar MR strategies, it is therefore possible that, in a

21 particular group, participants resorted to different strategies inveigh against the significance of 22 the results. Indeed, using six paper-and-pencil tests of spatial abilities, Hegarty and Waller 23 (2004) observed that each test have a dominant strategy, that there is some variability in the strategies used to solve all spatial tests and that no test is solved using the same strategy by all individuals. 

condition in which imagery ability is assessed. In agreement with the results of this study and tasks in AC rather than in TC.

\section{Conclusion}

The present study highlights the effect of tropical environment on mental rotation, as well as the necessity to take imagery ability into consideration. The results obtained in AC replicate the previous reported finding that men exhibit better spatial abilities than women. Moreover, the absence of main temperature condition effect showing no significant differences on the VMRT scores between TC and AC confirm the results generally observed in the literature (Hancock \& Vasmatzidis, 2003) if we consider that VMRT is not a very complex task. The fact that TC negatively influences men's performance prompts us to question the differential effects of heat and hygrometry. Moreover, the fact that MIQ-R scores were negatively affected by tropical condition, leads to wonder about the imagery ability stability depending on environmental conditions. It seems important to consider temperature the literature, it is reasonable to suggest that, at school or university in tropical environment, it 


\section{References}

Albaret, J.-M., \& Aubert, E. (1996). Test de rotation mentale de Vandenberg Etalonnage 1519 ans. Evolutions Psychomotrices, 8(34), 206-215.

Alexander, G. M., \& Evardone, M. (2008). Blocks and bodies: Sex differences in a novel version of the Mental Rotations Test. Hormones and Behavior, 53(1), 177-184. doi:10.1016/j.yhbeh.2007.09.014

Amos, D., Hansen, R., Lau, W.-M., \& Michalski, J. T. (2000). Physiological and cognitive performance of soldiers conducting routine patrol and reconnaissance in the tropics. Military Medecine, 165, 961-966.

Berg, R., Inaba, K., Sullivan, M., Okoye, O., Siboni, S., Minneti, M., Teixeira, P., \& Demetriades, D. (2015). The impact of heat stress on operative performance and cognitive function during simulated laparoscopic operative tasks. Surgery Volume, 157, 87-95. doi:10.1016/j.surg.2014.06.012

Chase, B., Karwowski, W., Benedict, M., Quesade, P., \& Irwin-Chase, H. (2003). A study of computer-based task performance under thermal stress. International Journal of Occupational Safety and Ergonomics, 9, 5-15. doi:10.1080/10803548.2003.11076550

Cian, C., Koulmann, N, Barraud, P. A., Raphel, C., Jimenez, C., \& Melin, B. (2000). Influence of variation in body hydration on cognitive function: Effect of hyperhydration, heat stress and exercise-induced dehydration. Journal of Psychophysiology, 14, 29-36. doi:10.1027//0269-8803.14.1.29

Cumming, J., \& Williams, S. (2012). Sport imagery ability predicts trait confidence and anxiety intensity and direction. Journal of Sport \& Exercise Psychology, 34, 220-229.

Debarnot, U., Piolino, P., Baron, J. C., \& Guillot, A. (2013). Mental rotation: effects of gender, training and sleep consolidation. PLoS One, 8, e60296. doi:10.1371/journal.pone.0060296 
1 Ernwein, V., \& Keller, D. (1998). Exercice musculaire et environnement thermique chaud: impacts sur les processus décisionnels chez des sportifs de grands terrains. [Effects of muscular calibrated exercise in a heated environment on a pointing task by football players]. Science et Sports, 13, 93-96. doi:10.1016/S0765-1597(97)86908-0

Gaoua, N. (2010). Cognitive function in hot environments: A question of methodology. Scandinavian Journal of Medecine \& Science in Sports, 20(3), 60-70. doi:10.1111/j.1600-0838.2010.01210.x

Guillot, A., Champely, S., Batier, C., Thiriet, P., \& Collet, C. (2007). Relationship between spatial abilities, mental rotation and functional anatomy learning. Advances in Health Science Educatio,. 12, 491-507. doi:10.1007/s10459-006-9021-7

Guillot, A., Collet, C., \& Dittmar, A. (2005). Influence of environmental context on motor imagery quality: An automatic nervous system study. Biology of Sport, 22, 215-226.

Guillot, A., Collet, C., Nguyen, V., Malouin, F., Richards, C., \& Doyon, J. (2008). Functional neuroanatomical networks associated with expertise in motor imagery ability. Neuroimage, 41, 1471-1483. doi: 10.1016/j.neuroimage.2008.03.042.

Guillot, A., Tolleron, C., \& Collet, C. (2010). Does motor imagery enhance stretching and flexibility? Journal of Sports Sciences, 28, 291-298. doi:10.1080/02640410903473828

Goss, S., Hall, C. R., Buckolz, E., \& Fishburne, G. J. (1986). Imagery ability and the acquisition and retention of movements. Memory and Cognition, 14, 469-477. doi:10.3758/BF03202518

Gur, R. C., Turetsky, B. I, Matsui, M., Yan, M., Bilker, W., Hughett, P., \& Gur, R. E. (1999). Sex differences in brain gray and white matter in healthy young adults: Correlations with cognitive performance. Journal of Neuroscience, 19, 4065-4072. 
1 Habacha, H., Molinaro, C., \& Dosseville, F. (2014). Effects of gender, imagery ability and sports practice on the performance of a mental rotation task. American Journal of Psychology, 127(3), 313-323.

Hall, C. R., Bernoties, L., \& Schmidt, D. (1995). Interference effects of mental imagery on a motor task. Brain Journal of Psychology, 86, 181-190. doi:10.1111/j.20448295.1995.tb02555.x

Hall, C. R., Buckolz, E., \& Fishburne, G. J. (1989). Searching for a relationship between imagery ability and memory of movements. Journal of Human Movement Studies, 17, 89-100.

Hall, C. R., \& Martin, K. (1997). Measuring movement imagery abilities: A revision of the movement imagery questionnaire. Journal of Mental Imagery, 21, 143-54. doi:10.1037/t07979-000

Hall, C. R., \& Pongrac, J. (1983). Movement Imagery Questionnaire. London, Ontario: University of Western Ontario.

Hancock, P., \& Vasmatzidis, I. (2003). Effects of heat stress on cognitive performance: The current state of knowledge. International Journal of Hyperthermia, 19, 355-372. doi:10.1080/0265673021000054630

Hancock, P. A., \& Warm, J. S. (1989). A dynamic model of stress and sustained attention. Human Factors, 31, 519-37. doi:10.7771/2327-2937.1024

Hegarty, M., \& Waller, D. (2004). A dissociation between mental rotation and perspectivetaking abilities. Intelligence, 32, 175-191.

Hocking, C., Silberstein, R. B., Lau, W. M., Stough, C., \& Roberts, W. (2001). Evaluation of cognitive performance in the heat by functional brain imaging and psychometric testing. Comparative Biochemistry and Physiology A Molecular Integrative Physiology, 128, 719-734. doi:10.1016/S1095-6433(01)00278-1 
1 Hoyek, N., Collet, C., Rastello, O., Fargier, P., Thiriet, P., \& Guillot, A. (2009). Enhancement of mental rotation abilities and its effect on learning. Teaching and Learning in Medicine, 21, 201-206. doi:10.1080/10401330903014178

Hoyeck, N., Collet, C., Fargier, P., \& Guillot, A. (2012). The use of the Vandenberg and Kuse Mental Rotation test in Children. Journal of Individual Differences, 33, 62-67.

Hoyek, N., Collet, $C$., \& Guillot, A. (2010). Représentation mentale et processus moteurs: le cas de la rotation mentale. Science \& Motricité, 71, 29-39. doi: 10.1051/sm/2009013

Isaac, A. (1992). Mental practice does it work in the field? The Sport Psychologist, 6, 192198.

Just, M. A., \& Carpenter, P. A. (1985). Cognitive coordinate systems: Accounts of mental rotation and individual differences in spatial ability. Psychological Review, 92, $137-$ 172.

Koslow, R. E. (2004). Sex-related differences and visual-spatial mental imagery as factors affecting symbolic motor skill acquisition. Sex Roles, 17, 521-527. doi:10.1007/BF00287733

Kosslyn, S. M.,Di Girolamo, G. J., Thompson,W. L.,\& Alpert, N. M. (1998). Mental rotation of objects versus hands: neural mechanisms revealed by positron emission tomography. Psychophysiology, 35,151-161. doi: 10.1111/1469-8986.3520151

Kosslyn, S. M., Thompson,W. L., Wraga, M., \& Alpert, N. M. (2001). Imagining rotation by endogenous versus exogenous forces: distinct neural mechanisms. Neuroreport,12, 2519-2525. doi:10.1097/00001756-200108080-00046

Kosonen, R., \& Tan, F. (2004). Assessment of productivity loss in air-conditioned buildings using PMV index. Energy Building, 36, 987-993. doi: 10.1016/j.enbuild.2004.06.021 
1 Lan, L., Lian, Z., Liu, W. \& Liu, Y. (2008). Investigation of gender difference in thermal comfort for Chinese people. European Journal of Applied Physiology, 102, 471-480. doi:10.1007/s00421-007-0609-2

Logie, R. H., Pernet, C. R., Buonocore, A., \& Della Sala, S. (2011). Low and high imagers activate networks differentially in mental rotation. Neuropsychologia, 49, 3071-3077. doi:10.1016/j.neuropsychologia.2011.07.011

Lorant, J., \& Nicolas, N. (2004). Validation de la traduction française du Movement Imagery Questionnaire - Revised (MIQ-R) [Validation of the French translation of the Movement Imagery Questionnaire-Revised (MIQ-R)]. Sciences \& Motricité, 53, 5768. doi:10.3917/sm.053.0057

Moffat, S. D., Hampson, E., \& Hatzipantelis, M. (1998). Navigation in a 'virtual' maze: Sex differences and correlation with psychometric measures of spatial ability in humans. Evolution and Human Behavior, 19, 73-87.

Monsma, E., Short, S., Hall, C., Gregg, M., \& Sullivan, P. (2009). Psychometric properties of the revised movement imagery questionnaire (MIQ-R). Journal of Imagery Research in Sport and Physical Activity, 4, 1-12. doi:10.2202/1932-0191.1027

Ozel, S., Molinaro, C. \& Larue, J. (2001). Influence of sport on gender differences in spatial imagery. Homeostasis in Health \& Disease, 41, 169-175.

Paivio, A. (1985). Cognitive and motivational functions of imagery in human performance. Canadian Journal of Applied Sport Sciences, 10, 22-28. Retrieved from http:// www.ncbi.nlm.nih.gov/pubmed/4085129.

Pepler, R. D. (1958). Warmth and performance: An investigation in the tropics. Ergonomics, 2, 63-88. doi:10.1080/00140135808930403

Qian, S., Li, M., Li, G., Liu, K., Li, B., Jiang, Q., Li, L., Yang, Z., \& Sun, G. (2015). Environmental heat stress enhances mental fatigue during sustained attention task 
performing: Evidence from an ASL perfusion study. Behavioral Brain Research, 280, 6-15. doi:10.1016/j.bbr.2014.11.036

Ramsey, J., \& Kwon, Y. (1992). Recommended alert limits for perceptual motor loss in hot environments. International Journal of Industrial Ergonomics, 9, 245-257. doi:10.1016/0169-8141(92)90018-U

Richardson, J. T. (1980). Mental Imagery and Stimulus Concreteness. Journal of Mental Imagery, 4, 87-97.

Richardson, J. T. (1995). Gender differences in the Vividness of Visual Imagery Questionnaire: A meta-analysis. Journal of Mental Imagery, 19, 177-187. doi:10.1080/03075079512331381760

Robin, N., Dominique, L., Toussaint, L., Blandin, Y., Guillot, A., \& Le Her, M. (2007). Effects of motor imagery training on returning serve accuracy in tennis: The role of imagery ability. International Journal of Sport \& Exercise Psychology, 2, 177-188. doi:10.1080/1612197X.2007.9671818

Salati, E., Lovejoy, T. E., \& Vose, P. B. (1983). Precipitation and water recycling in tropical rain forests with special reference to the amazon basim. Environmentalist, 3, 67-72. doi: 10.1007/BF02240058

Schack,T., Essig, K., Frank, C., Koester, D. (2014). Mental representation and motor imagery training. Frontiers in Human Neuroscience, 8, 1-10. doi: 10.3389/fnhum.2014.00328

Seiler, B., Monsma, E., \& Newman-Norlund, R. (2015). Biological evidence of imagery abilities: Intraindividual differences. Journal of Sport and Exercise Psychology, 37, 421-35. doi:10.1123/jsep.2014-0303

Seurinck, R., Vingerhoets, G., de Lange, F. R., \& Achten, E. (2004). Does egocentric mental rotation elicit sex differences? Neuroimage, 23, 1440-1449. doi:10.1016/j.neuroimage.2004.08.010 
1 Shepard R. N., \& Metzler, J. (1971). Mental rotation of three-dimensional objects. Science, 171, 701-703. doi:10.1126/science.171.3972.701

Sirigu, A., \& Duhamel, J.R. (2001). Motor and visual imagery as two complementary but neurally dissociable mental processes. Journal of Cognitive Neurosciences, 13, 910 919. doi:10.1162/089892901753165827

Titze, C., Jansen, P., \& Heil, M. (2010). Mental rotation performance and the effect of gender in fourth graders and adults. European Journal of Developmental Psychology, 7, 432444. doi:10.1080/17405620802548214

Tomasino, B., \& Gremese, M. (2016). Effects of Stimulus Type and Strategy on Mental Rotation Network: An Activation Likelihood Estimation Meta-Analysis. Frontiers in Neuroscience, 9, 1-26. doi: 10.3389/fnhum.2015.00693

Toussaint, L., Robin, N., \& Blandin, Y. (2010). On the content of sensorimotor representations after actual and motor imagery practice. Motor Control, 14, 159-175.

Vandenberg, S. G., \& Kuse, A. R. (1978). Mental rotations, a group test of three dimensional spatial visualization. Perceptual and Motor Skills, 47, 599-604. doi:10.2466/pms.1978.47.2.599

Vasmatzidis, I., Schlegel, R., \& Hancock, P. (2002). An investigation of heat stress effects on timesharing performance. Ergonomics, 45, 218-39. doi:10.1080/00140130210121941

Vogel, J. J., Bowers, C. A., \& Vogel, D. S. (2003). Cerebral lateralization of spatial abilities: A meta-analysis. Brain and Cognition, 52(2), 197-204. doi:10.1016/S02782626(03)00056-3

Voyer, D. (1996). The relation between mathematical achievement and gender differences in spatial abilities: A suppression effect. Journal of Educational Psychology, 88, 563571. doi:10.1037/0022-0663.88.3.563 
1 Voyer, D. (1997). Scoring procedure, performance factors, and magnitude of sex differences in spatial performance. American Journal of Psychology, 110, 259-276. doi:10.2307/1423717

4 Wexler, M., Kosslyn, S., \& Berthoz, A. (1998). Motor processes in mental rotation. Cognition 5 68, 77-94.

6 Williams, E., Cumming, J., Ntoumanis, N., Nordin-Bates, S. M., Ramsey, R., \& Hall, C. R. (2012). Further validation and development of the movement imagery questionnaire. Journal of Sport \& Exercise Psychology, 34, 621-646. Retrieved from http://journals.humankinetics.com/jsep

Wohlschläger, A., \& Wohlschläger, A. (1998). Mental and manual rotation. Journal of Experimental Psychology: Human Perception and Performance, 24, 397-412. doi:10.1037/0096-1523.24.2.397

Wyon, D.P., Andersen, I. \& Lundqvist, G.R. (1972). Spontaneous magnitude estimation of thermal discomfort during changes in the ambient temperature. Journal of Hygiene, 70, 203-221. 